There are numerous reports of distal $4 \mathrm{q}$ deletions and recognisable syndromes resulting from $\operatorname{del}(4)(\mathrm{q} 31)$. and $\operatorname{del}(4)(q 33)$ are well defined, ${ }^{1}$ but only seven

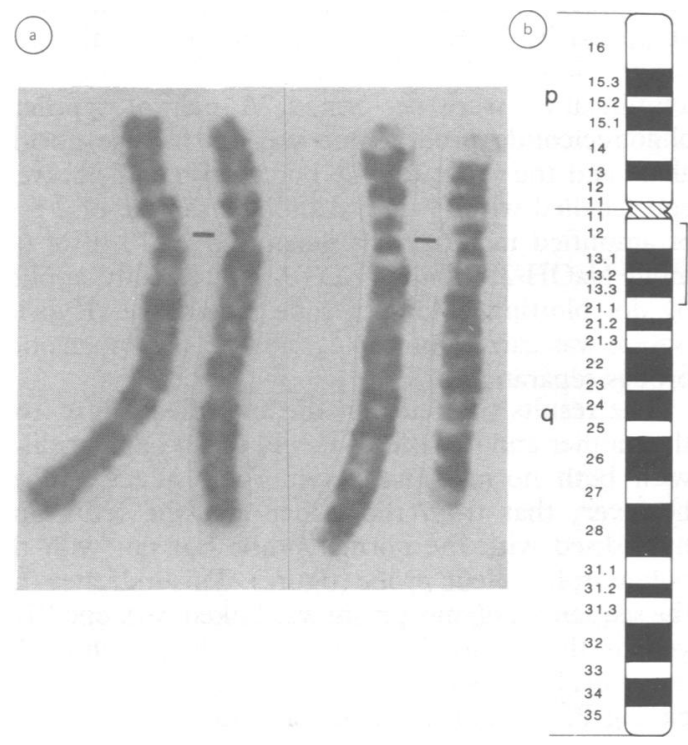

Figure 2 (a) Partial karyotype, GTG banding (right) and $R B G$ banding (left). The deleted chromosome is on the right in each pair. (b) Diagram of chromosome 4 showing location of the deleted segment. children with proximal deletions involving bands $4 \mathrm{q} 12$ to $4 \mathrm{q} 21$ have been described. ${ }^{12}$ Our patient shows a number of features in common with those previously reported, notably mental retardation, developmental delay, feeding difficulties, poor growth and small size, hypotonia, abnormal facies, and unusually shaped head with domed forehead and abnormal ears. In addition, he has bilateral colobomata, which has not been previously documented. He did not, however, have the disproportionally small hands and feet, depressed nasal bridge, seizures, or pigmentary changes that have been described elsewhere.

Clinical variation between people with proximal $4 \mathrm{q}$ deletions including bands $4 \mathrm{q} 12$ to $4 \mathrm{q} 21$ is most likely attributable to the patients having slightly different deletions involving overlapping sets of genes. Molecular analysis of the deletions, which will more precisely define the breakpoints, should enable more accurate phenotype-deletion correlation.

1 Lin AE, Garver KL, Diggans G, et al. Interstitial and terminal deletions of the long arm of chromosome 4: further delineation of phenotypes. Am 7 Med Genet 1988;31:533-48.

2 Beall $M H$, Falk RE, Ying K-L. A patient with an interstitial deletion of the proximal portion of the long arm of chromosome 4. Am f Med Genet 1988;31:553-7.

\title{
Application of a new DNA sequence polymorphism as a genetic marker in prenatal diagnosis of phenylketonuria
}

\author{
Shu-zhen Huang, Zhao-rui Ren, Yi-tao Zeng
}

Classical phenylketonuria (PKU), a severe inborn error of amino acid metabolism with an incidence of about 1 in 16000 Chinese births, is caused by absence of hepatic phenylalanine hydroxylase (PAH). DNA analysis has been used to detect mutations at the PAH locus and to provide prenatal diagnosis for fetuses at risk for PKU. ${ }^{12}$ Recently, an $\mathrm{A} \rightarrow \mathrm{T}$ substitution at

Laboratory of Medical Genetics, Shanghai Children's Hospital, 380 Kang Ding Road, Shanghai 200040, China. S Z Huang, Z R Ren, Y T Zeng

Correspondence to Dr Zeng.

Received for publication 20 June 1989. Accepted for publication 23 June 1989. codon 398 of the PAH gene in the Chinese has been found and described as a new DNA sequence polymorphism (S Z Huang et al, unpublished data). Here we report the use of this sequence polymorphism as a genetic marker for prenatal diagnosis of PKU by DNA amplification with PCR and oligonucleotide hybridisation.

A young couple, who already had one child with PKU, consulted us and asked for prenatal diagnosis during the eighth week of gestation (figure). RFLP analysis in this family showed no heterozygosity apart from the $E c o$ RI polymorphic site, and the father, mother, the child with PKU, and the fetus all had both the $17 \mathrm{~kb}$ and $11 \mathrm{~kb} E$ coRI fragments. Accordingly, the fetus had a $50 \%$ chance of being normal and 

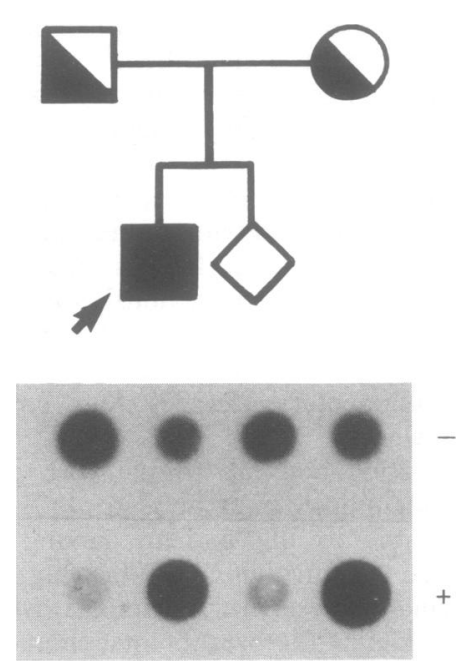

- Normal ASO probe

+ Polymorphic ASO probe

Pedigree of a PKU family and DNA dot blot hybridisation using PCR/ASO probes.

a $50 \%$ chance of having PKU. Therefore, no prediction could be made based on RFLP analysis.

Fortunately, the sequence polymorphism at codon 398 of the PAH gene was found in this family. To complete the prenatal diagnosis, we designed and constructed a pair of oligonucleotide primers, 5'CTGATCCTGATTTAACAGTG- $3^{\prime}$ and 5'-AGTCCACTCTCCTGGAACCA-3', to direct enzymatic amplification of a 266 bp DNA fragment spanning $3^{\prime}$ of exon 11 plus the flanking intronic regions in the PAH gene and involving the codon 398 sequence.

DNA $(0.5 \mu \mathrm{g})$ samples from the child with PKU, his father and mother, and chorionic villi were amplified by PCR using a modification of the procedure described by Kogan et $a l^{3}{ }^{3}$ Thirty cycles of amplification were performed. A pair of synthetic oligonucleotide probes, one specific for the normal allele and the other for the polymorphic allele, were end labelled with $\left[\gamma-{ }^{32} \mathrm{P}\right]$ dATP. A sample of $2.5 \mu \mathrm{l}$ of amplified material was denatured in $10 \mu \mathrm{l}$ of 0.4 $\mathrm{mol} / 1 \mathrm{NaOH} / 25 \mathrm{mmol} / \mathrm{l}$ EDTA and directly applied by dot blotting onto zetaprobe membrane. Hybridisation was carried out using labelled oligonucleotide probes separately.

The results showed that the amplified DNA from the mother and the affected child could be hybridised with both normal and polymorphic allelic probes; however, that from the father and the fetus only hybridised with the normal probe but not with the polymorphic allelic probe (figure). This indicates that the sequence polymorphism was linked with one PKU gene in this family. The fetal DNA did not show this polymorphism, so the fetus could be excluded from having PKU. This approach provides a new way for the effective prenatal diagnosis of PKU.

1 DiLella AG, Huang WM, Woo SLC. Screening for phenylketonuria mutations by DNA amplification with polymerase chain reaction. Lancet 1988;i:497-9.

2 Zeng YT, Xue JR, Zhang ML, et al. Prenatal diagnosis of phenylketonuria (10 case reports). Natl Med $\mathcal{F}$ China 1988;68: $61-4$.

3 Kogan SC, Doherty M, Gitschier J. An improved method for prenatal diagnosis of genetic diseases by analysis of amplified DNA sequence. Application to hemophilia A. N Engl $\Im$ Med 1987;317:985-90. 